\title{
Polis en conflicto: memoria urbana del Golpe de Estado de septiembre de 1973 en Valparaíso, Chile
}

\section{Polis in conflict: urban memory of the Coup d'Etat in September 1973. Valparaiso, Chile}

\author{
Patricia Castañeda Meneses \\ Doctora en Ciencias de la Educación. Académica e Investigadora de la Escuela de Trabajo Social. Facultad de Ciencias Sociales. Universidad de \\ Valparaíso. Avda. Colón 2128 (CP 2340000) Valparaíso, Chile, patricia.castaneda@uv.cl \\ Ketty Cazorla Becerra \\ Magister en Salud Pública. Académica e Investigadora de la Escuela de Trabajo Social. Facultad de Ciencias Sociales. Universidad de Valparaíso. \\ Avda. Colón 2128 (CP 2340000) Valparaíso, Chile, ketty.cazorla@uv.cl \\ Katherine Cuevas Lang \\ Magister en Salud Pública. Académica e Investigadora del Departamento de Salud Pública de la Escuela de Medicina. Universidad de Valparaíso. \\ Avda.Angamos 655 (CP 2520000) Reñaca, Viña del Mar, Chile, katherine.cuevas@uv.cl
}

Recibido: 24 de julio 2019 || Aprobado: 16 de abril 2020

\section{Resumen}

En Chile, el 11 de septiembre de 1973 se produce un Golpe de Estado que inicia una dictadura cívico militar que se extendió hasta marzo de 1990. El presente trabajo tiene por objetivo rescatar la memoria urbana de la población mayor de Valparaíso respecto del desarrollo del Golpe de Estado en la ciudad. Se realizó un trabajo de campo aplicando 32 entrevistas cualitativas de enfoque biográfico. Los resultados indican que la memoria de la ciudad reconoce en el Golpe de Estado un hito que fracturó la polis a través de la ruptura del espacio político ciudadano debido a la intervención militar. Como consecuencia, las relaciones entre el Estado y la ciudadanía quedaron retenidas dentro de un marco dictatorial de 17 años, aportando un complejo legado de confrontación urbana definida desde el conflicto y la hostilidad.

Palabras clave: Memoria Urbana; Ciudad; Ciudadanía; Golpe de Estado

Abstract

In Chile, on September 11, 1973, there was a Coup d'Etat that initiated a military-civic dictatorship that was extended until March 1990. The purpose of this work is to rescue the urban memory of the older population of Valparaíso regarding the development of the Coup d'Etat in the city. A fieldwork was carried out applying 32 qualitative interviews with a biographical approach. The results indicate that the memory of the city recognizes in the Coup d'Etat a milestone that fractured the polis through the rupture of the citizen political space due to military intervention. As a consequence, relations between the State and the citizenry were retained within a dictatorial framework of 17 years, providing a complex legacy of urban confrontation defined from the conflict and hostility.

Key words: Urban memory; City; Citizenship; Coup d'Etat

Cita sugerida: Castañeda Meneses, P.; Cazorla Becerra, K. y Cuevas Lang, K. (2020). Polis en conflicto: memoria urbana del Golpe de Estado de septiembre de 1973 en Valparaíso, Chile. Estudios Socioterritoriales. Revista de Geografía, (27), 047. DOI: //https://doi.org/10.37.838/unicen/est.27-047 


\section{INTRODUCCIÓN}

Desde la antigua tradición griega, la polis fundada en la democracia es considerada la primera forma de participación política y el escenario en que se expresa la triada compuesta por la ciudad, el Estado y la ciudadanía (Carrión, 2007). Para Hernández Aja (2000) la ciudad puede ser definida como un espacio público de convivencia social al servicio de la ciudadanía democrática. Por oposición, para Alguacil (2008) la ciudad también puede ser concebida como un espacio de conflicto a partir del encuentro de ciudadanos libres que se adscriben a posiciones diferentes. Así entonces, el conflicto motiva la política y transforma el espacio público en un espacio político, en donde puede manifestarse por una parte la búsqueda del diálogo y la negociación en los espacios institucionales formalmente definidos; o por otra parte, la confrontación y la beligerancia entre posiciones, situación preferentemente manifestada en las principales avenidas de la ciudad y en espacios poblacionales periféricos. Cuando el conflicto se expresa a través de violencia explícita en el espacio urbano, las relaciones conflictivas se constituyen en una forma de comportamiento social que transforma a la ciudad en el principal escenario en donde se despliegan las hostilidades (Franco, 2003). En consecuencia, el territorio estará siempre vinculado con el poder y con el control de los procesos sociales que se suceden dentro de sus límites y su definición tendrá como referencias centrales a las relaciones sociales y al contexto histórico en el que se inserta (Haesbaert, 2013).

En Chile, a septiembre de 1973 el espacio urbano constituía un espacio político que expresaba abiertamente un profundo conflicto de posiciones a favor y en contra del Gobierno del Dr. Salvador Allende Gossens. El mandatario había asumido como Presidente de la República con fecha 4 de noviembre de 1970 por el período constitucional de seis años. En su calidad de representante de la coalición de fuerzas de centro izquierda denominada Unidad
Popular había obtenido una mayoría relativa de $36,6 \%$ del total de votos válidamente emitidos, seguido estrechamente por el candidato de la derecha tradicional que alcanzó el 35,3\% de preferencias. Cerraba los resultados el candidato del sector de la Democracia Cristiana con un $15,4 \%$ de sufragios. En ese contexto, se suscribió un acuerdo entre la Unidad Popular y el Partido Demócrata Cristiano denominado Pacto de Garantías Constitucionales, que permitió respaldar y confirmar el triunfo electoral de la Unidad Popular. No obstante, en un tenso marco geopolítico internacional correspondiente a la Guerra Fría y de aplicación de la Doctrina de Seguridad Nacional, el triunfo electoral fue ratificado por el Congreso Pleno conforme la Constitución vigente, en medio de fuertes tensiones políticas internas e importantes presiones internacionales (Leal, 2003). El momento cúlmine que expresó el clima de tensión política extrema que se vivía, fue el secuestro y asesinato del Comandante en Jefe del Ejército en ejercicio, acción sucedida días antes del pronunciamiento del Congreso y concebida como medida de presión que buscaba evitar la confirmación de los resultados electorales presidenciales por parte del poder legislativo ${ }^{1}$. Este hecho imprimió un

1 En octubre de 1970, el General René Schneider Chereau era Comandante en Jefe del Ejército de Chile y férreo defensor de la posición constitucionalista no deliberante de las Fuerzas Armadas. El intento de secuestro desarrollado en su contra buscaba presionar al Congreso Nacional para que, contrario a la tradición republicana vigente a la fecha, no se confirmara al candidato socialista Salvador Allende como Presidente de la República, dada la primera mayoría relativa que había obtenido en las elecciones presidenciales de septiembre de 1970. Esta atribución estaba establecida en la Constitución y era aplicada en forma regular en la tradición democrática del país, debido a que al no contemplar segunda vuelta electoral, cada elección arrojaba resultados que se distribuían en forma homogénea entre las fuerzas políticas de derecha, centro e izquierda, situación que fue conocida como los tres tercios, no permitiendo alcanzar mayorías absolutas en cada proceso electoral, forzando la confirmación de parte del Congreso. La inexperiencia del comando que secuestró al General Schneider le ocasionó graves heridas de bala que le ocasionaron la muerte los días posteriores. Su deceso generó un hondo impacto en la opinión pública y anticipó el difícil y polarizado período que se iniciaba con la confirmación de Allende como presidente del país y que culminaría con el Golpe de Estado de septiembre de 1973. Investigaciones posteriores confirmaron la influencia norteamericana y la presencia de la extrema derecha en la planifica- 
ambiente de inestabilidad y confrontación política al país, que se fue radicalizando conforme avanzaron los años de gestión del gobierno de Allende (Aguilera, 2013).

El principal pilar de apoyo del triunfo electoral de la Unidad Popular habían sido los movimientos de pobladores, sindicatos y fuerzas campesinas (Cortés, 2014), fuerzas sociales que aspiraban a iniciar la construcción del socialismo en Chile en el marco de la legalidad vigente, tal como lo declaraba el programa de gobierno de la Unidad Popular (1970). Sus principales detractores correspondían a los sectores de ingresos medios y altos del país, que cuestionaban ideológicamente las medidas gubernamentales y que se encontraban respaldados por partidos políticos conservadores, grupos empresariales, sectores de las Fuerzas Armadas y por el gobierno de Estados Unidos, velado colaborador en la organización y financiamiento de acciones destinadas a la desestabilización política del país (Arellano, 2009; Agüero, 2003; Kornbluh, 2004; Lira, 2013). Este álgido contexto se expresaba cotidianamente a lo largo del país a través de violentas manifestaciones, contramanifestaciones y enfrentamientos callejeros, circulación de prensa partidista, organización de grupos paramilitares, desabastecimiento de bienes básicos, acciones de sabotaje, crecientes conflictos en el sector productivo y llamados a prolongadas paralizaciones por parte de organismos gremiales y profesionales. En consecuencia, el conflicto rápidamente escaló de sus límites políticos formales institucionales y se desplegó en forma transversal en toda la sociedad chilena.

Los plazos constitucionales extendían el mandato del Presidente Allende hasta el 4 de noviembre de 1976, horizonte temporal que resultaba insostenible para los grupos de mayor

ción del intento de secuestro y en la protección de los asesinos, facilitando su salida al extranjero en los días posteriores al asesinato. La muerte del Comandante en Jefe dio origen a lo que se conoció como la Doctrina Schneider, que situaba a las Fuerzas Armadas como garantes de la institucionalidad del país sin injerencia en la política contingente. Esta doctrina fue abandonada a partir del Golpe de Estado de 1973 (Cavallo, Salazar y Sepúlveda, 1988). resistencia. La posibilidad de concretar un Golpe de Estado por parte de las Fuerzas Armadas, fue conceptualizada como la única vía posible para salvar al país de una guerra civil y defenderlo de las amenazas internas y externas asociadas al avance del comunismo (Waldman, 2009). Con apoyo de sectores civiles, gremiales y empresariales, el 11 de septiembre de 1973 se concreta el Golpe de Estado en Chile, siendo ejecutado en forma directa por las Fuerzas Armadas y de Orden. Las principales ciudades del país, junto con la ciudad capital, fueron foco preferente de las acciones desarrolladas ese día y sus experiencias remiten a la memoria urbana de una fecha que fracturó la continuidad de la historia ciudadana del país.

En este marco, el presente artículo se plantea como objetivo rescatar la memoria urbana de la población mayor de Valparaíso respecto del desarrollo del Golpe de Estado, evento cuyos alzamientos iniciales se suceden en la misma ciudad, dando origen a 17 años de dictadura cívico-militar en el país. La investigación se orienta por los estudios de memoria colectiva en el marco de la historia reciente de Chile (Aróstegui, 2004). El concepto de memoria colectiva es acuñado por Halbwachs (1950, p. 15) quien la define como "el proceso social de reconstrucción del pasado vivido y experimentado por un determinado grupo, comunidad o sociedad, a través de marcos de memoria asociados a fechas socialmente significativas en lo temporal y a lugares representativos en lo espacial". Para Cruz (2003) la memoria hace posible la existencia del pasado, dotando de significados las dimensiones materiales e inmateriales de la gente que vive en sociedad y se comporta en consecuencia. A partir de la referencia a la memoria colectiva, Campos y López (2004) proponen el concepto de memoria urbana, basado en

la identidad colectiva de un conjunto de personas respecto del territorio que ocupan, que les permite sacralizar los vínculos que una persona o grupo tienen con su espacio específico, apreciado más allá de su valor de uso, al concentrar sentidos vinculados a la emotividad, a la historia, a la experiencia o a ciertos elementos que 
se consideran propios y fundamentales para la representación de valores y visiones que se tienen de la realidad. (p.2)

Complementariamente, Alba define la memoria urbana como resultado del análisis de las experiencias de vida de envejecer en la ciudad, considerando el espacio urbano como "un sistema de signos que al ser interpretados por sus residentes, transforma la ciudad en un libro de piedra en que está impresa materialmente la historia de la sociedad que la ha construido" (2010, p. 4-5).

Esta perspectiva permite recuperar los recuerdos de los actores sociales que han dejado testimonios de la vida pasada. La ciudad es entonces el campo del quehacer político, social y cultural en el que los distintos actores han construido su espacio de vida a través de sus intervenciones. Membrado (2010) identifica la presencia de fuertes valores afectivos, simbólicos y temporales de la población que habita un territorio a lo largo de su vida, construyendo una relación con su ciudad, que reconocen la pertenencia social a un conjunto, a un colectivo y a una memoria urbana. Reguillo Cruz (1991) plantea que la ciudad es un espacio en disputa de distintas visiones de mundo asociadas a posiciones sociales y simbólicas presentes en el territorio, las que se traducen en los territorios de la memoria. Estos territorios se producen a partir de acciones reivindicativas desarrolladas por sujetos y colectividades que pueden ser acogidas por instituciones públicas o ser resignificadas por estrategias conmemorativas de carácter auto convocado que expresan la identidad de los actores sociales que promueven la memoria en el territorio (Raposo, 2012).

La memoria urbana involucra un espacio y un tiempo en el que ocurren determinados hechos, evocados a través de múltiples discursos y significados, que comunican las circunstancias o necesidades presentes que requieren sentido y comprensión. Para acceder a este acervo se debe recurrir a la memoria de las propias personas, quienes reconstruyen los hechos a través de sus propias vivencias, las que son in- terpretadas y enmarcadas en su subjetividad y en su cultura, usando preferentemente en su expresión el lenguaje narrativo, lo que conlleva una elaboración consciente, reflexiva y analítica del relato que comunican. Por tanto la estrategia de recolección de información debe ser coherente con la noción de testigo y testimonio que evoca la memoria colectiva, frente al hecho traumático que le da origen.

Para efectos de la presente investigación se definió como marco temporal de la memoria urbana investigada el día 11 de septiembre de 1973, fecha en que sucede el Golpe de Estado en Chile, organizado a partir de las siguientes dimensiones: a) período inmediatamente anterior al Golpe de Estado; b) día 11 de septiembre de 1973 en que ocurre el Golpe de Estado; y c) período inmediatamente posterior a la ocurrencia del Golpe de Estado. El marco espacial de memoria urbana corresponde a la ciudad de Valparaíso, capital de la Región de Valparaíso, primer puerto naval y comercial del país y base de las principales dependencias, servicios y reparticiones de la Armada Nacional.

Se realizó un trabajo de campo con enfoque cualitativo entre los meses de mayo de 2018 a enero del 2019, aplicando un total de 32 entrevistas a personas mayores en calidad de informantes claves. La selección de informantes fue realizada por medio de una invitación abierta a participar de la investigación, en atención a su calidad de residentes permanentes en la ciudad de Valparaíso y a su trayectoria como dirigentes comunitarios de sectores poblacionales históricos de la ciudad. La cantidad de personas entrevistadas se definió desde el criterio de saturación teórica. La técnica de recolección de información correspondió a entrevista cualitativa con enfoque biográfico, definida como una narrativa centrada en los eventos vitales de cada sujeto, cuyos resultados se revisan con fines de análisis científico (Valles, 2002). El guion temático se diseñó a partir de preguntas abiertas asociadas a las experiencias relativas al Golpe de Estado en la ciudad de Valparaíso que tuvieron las personas mayores participantes de la inves- 
tigación. Las preguntas fueron organizadas a partir de las dimensiones temporales y espaciales definidas para el estudio.

Las entrevistas tuvieron una duración promedio de noventa minutos. Cada entrevista fue grabada en audio y transcrita para fines de análisis cualitativo. Los relatos de las experiencias vitales fueron organizados por dimensiones temporales y segmentadas en unidades significativas que respaldaron el sistema de categorías y subcategorías, constituyendo los referentes desde donde se analizaron los resultados. Para otorgar validez y confiabilidad a los resultados obtenidos, se aplicaron los criterios de rigor cualitativos correspondientes a credibilidad, transferibilidad y confirmabilidad, a través de los procedimientos de interanálisis, desarrollo de descripciones minuciosas y utilización de descriptores de baja inferencia.

El proyecto de investigación que da origen al presente artículo se denomina "Sentidos del Lugar y Memorias Urbanas: Envejecer en Valparaíso" y fue financiado por el Convenio de Desempeño PMI UVA 1401 Gerópolis Modelo de educación, salud y territorio: Enfrentando la desigualdad en la tercera edad en la ciudad de Valparaíso, implementado por la Universidad de Valparaíso, Chile. Asimismo, contó con el patrocinio institucional de la Oficina Comunal del Adulto(a) Mayor y la Oficina Comunal de Vivienda, Barrio y Ciudad de la Ilustre Municipalidad de Valparaíso, Chile.

Respecto a las consideraciones éticas, debe señalarse que las personas mayores participantes invitadas a colaborar con la investigación poseían rangos de autonomía personal que les permitía discernir sobre su voluntad de participar en el estudio y ejercer su capacidad legal para dar su consentimiento. Toda participación de las personas mayores en el proceso de levantamiento de información estuvo precedida por la entrega de antecedentes relativos a los objetivos del estudio, tipo de participación esperada, procedimientos de levantamiento de datos y compromiso de confidencialidad en el uso, tratamiento y modalidad de publicación de los datos recabados. La participación de cada persona se formalizó mediante la firma voluntaria en documento de consentimiento informado que presentaba por escrito los antecedentes señalados. Cada consentimiento informado fue firmado en dos ejemplares, quedando un ejemplar en poder de cada persona mayor participante y otro ejemplar bajo custodia del equipo de investigación. Para el análisis de los datos se identificó a cada persona con un código alfanumérico con el fin de proteger la confidencialidad en el uso de la información. El proyecto de investigación fue evaluado y aprobado en sus aspectos éticos por el Comité de Bioética de la Facultad de Medicina de la Universidad de Valparaíso.

\section{RESULTADOS}

Conforme con los marcos temporales y espaciales definidos para el rescate de la memoria urbana relativa al Golpe de Estado en Valparaíso, los resultados se presentan organizados a partir de las tres dimensiones declaradas para la investigación.

a) Período inmediatamente anterior al Golpe de Estado.

Las personas mayores entrevistadas evocan una gran tensión social durante el período 1970 1973, expresada principalmente a través de escaramuzas en diversos sectores de la ciudad sucedidas entre defensores y detractores del gobierno de Allende. Las irreconciliables posiciones políticas se fueron incrementando durante el año 1973, llegando a su punto máximo en las semanas previas al Golpe de Estado.

\footnotetext{
Ese tiempo fue terrible por las peleas en las calles. Cortaban la luz. Le tiraban unos cordeles con piedra a los cables de la luz y cortaban la luz. Había que hacer cola (filas) desde las cinco de la mañana para conseguirse una presa de pollo, para conseguir leche. Así que fue una época tremenda y no se vivía tranquila. (Persona mayor, 82 años)
}

La tensión en la ciudad se fue acrecentando en la medida que el clima político se polarizaba entre sectores antagonistas. Las personas recuerdan que esta situación era reconocida con temor a nivel familiar y social. "Fue un periodo 
como de susto. De susto, porque lo que uno escuchaba a los papás era que el gobierno estaba mal. De que tenían miedo de lo que estaba sucediendo" (Persona mayor, 68 años).

En un ambiente enrarecido, la población se enfrentaba a una dinámica de creciente incertidumbre frente a la posibilidad de ocurrencia de sucesos de mayor gravedad en el marco de la abierta beligerancia que afectaba al espacio urbano. La intervención militar se viabilizaba como una opción real en el marco de una ciudad en conflicto. "La gente andaba con susto, se notaba un ambiente de que podía pasar algo" (Persona mayor, 61 años).

b) Día 11 de septiembre de 1973 en que ocurre el Golpe de Estado

El Golpe Militar en Chile se inicia en la ciudad de Valparaíso, a través de los movimientos de la escuadra y tropas de la Armada, a la que se plegarían concertadamente a lo largo del país las instituciones de la Defensa Nacional correspondientes al Ejército y la Fuerza Aérea, junto con la institución de Carabineros de Chile, responsable del orden público.

Esa madrugada recorrí Valparaíso y el ambiente era denso, pesado. Me fui al local del partido a ver si tenían alguna novedad y me dicen que es la noche más delicada (...) Se sabía que se había iniciado un movimiento de tropas en el puerto y en algunas zonas de la ciudad. (Persona mayor, 81 años)

Las primeras evidencias de las movilizaciones militares en el plan de la ciudad son desestimadas inicialmente, asumiendo que son la continuidad del clima de tensión social que había caracterizado los últimos meses del año 1973:

Él me dice lo siguiente. Mire, el marino que está cuidando el monumento a Prat está muerto de frío. La oficina de la Primera Zona Naval está con luz y con los mismos marinos que están de guardia. Están ahí. No pasa nada. ¿Y la escuadra? pregunté. Zarpó. Están en un ejercicio con la operación UNITAS ${ }^{2}$ y no han vuelto. Así que no. No va a pasar nada. Estas advertido. Ten cuidado. Cualquier cosa llámame por la radio. (Persona mayor, 81 años)

El funcionamiento normal de la ciudad comenzó a ser interrumpido en forma gradual,

2 Operación de ejercicios conjuntos de cooperación naval realizados anualmente entre las Armadas de Estados Unidos y Chile (Cavallo et al., 1988). siendo percibido el inusual movimiento de las tropas en los distintos sectores poblacionales.

Dejaron de pasar las micros (buses). Amaneció y venía la gente de vuelta. Venía mucha gente caminando hacia arriba donde estaban las casas. Porque los estaban devolviendo a todos. Algo pasaba. Salieron todos los militares a la calle, las tanquetas. Uno decía ¿qué pasó? Y bueno, ahí todos con una radio puesta. Era del terror. Había que esconderse y no salir a la calle. (Persona mayor, 61 años)

Con el correr de las horas, la ocupación militar de la ciudad se va concretando a través de la movilización de las fuerzas militares en actitud de combate y civiles colaboradores.
Bueno. Voy a ir a mirar al sector oriental de Valparaíso (...) donde están todas las escuelas de suboficiales, arti- Ilería, ingeniería naval. Todas las escuelas de formación. $Y$ hay regimientos, sobre todo de la marina. Voy para allá y me encuentro con una columna (...) una columna de camiones del Sindicato de Dueños de Camiones. Más atrás, camiones artillados con metralleta punto 30 en el techo. (Persona mayor, 81 años)

En medio del desconcierto, se intentó organizar una respuesta de resistencia de parte de los pobladores leales al gobierno de Allende. Sin embargo, se constató que no se poseían los medios para enfrentar a la fuerza militar.

Toda la gente se juntó en la esquina del mural y todos pedían armas para defender al gobierno popular. Entonces se había dicho que se iba a defender al gobierno que había un estado de ánimo de lucha, de querer defender lo que tanto había costado en la historia... que fuera a ser derrocado (...) Llamamos a la gente que podía saber y no había nada. Algunos tenían una escopeta de casa. No, eso no sirve. Guárdelo porque se puede volar la mano. Nosotros queríamos organizarnos, establecer la defensa del gobierno popular, estábamos dispuestos. Pero no había con qué. ¿Con piedras? ¿Con flechas?... ¡con que! No teníamos nada. (Persona mayor, 78 años)

Al término de la mañana, la ocupación de los sectores estratégicos de Valparaíso ya había sido concretada y comenzaba el control militar respecto de la circulación de personas.

Bajó un camión del cerro Esperanza con trabajadores de la compañía de gas (...) Les dijimos que no bajaran, que la avenida España estaba ocupada; que ya habían ocupado el retén Portales -donde está el matadero- ya lo habían ocupado los marinos. La (Universidad) Santa María ya estaba ocupada por la Armada. El gasómetro, que es una compañía de gas, que es un sitio estratégico, también ahí. 
Les dijimos a los trabajadores, que la mayoría eran socialistas, no vayan porque los pueden detener en Portales o encajonar en la Avenida España. Portales ya está ocupado por los marinos, la gente ya sabía porque subía. Y al rato, el camión vuelve con los mismos trabajadores. Tenían razón, no pudimos bajar. (Persona mayor, 81 años)

En el marco de los hechos que fueron sucediendo en Valparaíso, algunos sectores de la ciudad recibieron el Golpe de Estado de manera favorable, por lo que las expresiones de alegría se sucedieron de manera espontánea.

Cuando recién fue el golpe, había personas que sintieron felicidad por lo que estaba pasando. Toda la gente feliz, cantando. Saliendo feliz para afuera. No, si fue de mucha felicidad. Salieron con banderas, todo eso. Música. Pusieron banderas en las casas, todo eso. (Persona mayor, 82 años)

En la ciudad capital, Santiago de Chile, el Golpe de Estado había comenzado en la madrugada. Durante toda la mañana las fuerzas militares atacan La Moneda, el Palacio Presidencial en donde el presidente Allende resiste junto a un grupo de colaboradores. En ese contexto, el mandatario se dirige al país -en el que a la postre será su último mensaje presidencial- desde radio Magallanes, una de las pocas radioemisoras que resistía a las instrucciones militares de silenciar trasmisiones y adherirse a la entrega de información oficial emitida por la Junta Militar a partir de bandos o comunicados. Este mensaje es escuchado de manera clandestina en la ciudad y a partir de ello, se comenzaron a definir las acciones de sobrevivencia de quienes se encontraban comprometidos con el gobierno derrocado.

Alrededor de las 10 de la mañana ya habíamos escuchado el discurso de Allende. Putas, todos llorando. Todos tristes. Ahora, lo mejor es replegarse y salvar la vida. Que no nos encarcelen. Cuídense ustedes. Tengan cuidado, porque lo que viene es tremendo. El fascismo desatado es muy cruel. No nos van a perdonar haber querido cambiar este Chile. Terminar con los privilegios de clase, la discriminación, la desigualdad social. (Persona mayor, 78 años)

Cerca del mediodía La Moneda es bombardeada $^{3}$. La información recorrió el país a tra-

3 El bombardeo de La Moneda estuvo a cargo de la Fuerza Aérea de Chile. Al mediodía de martes 11 de septiembre de 1973 una flotilla de aviones Hawker Hunter atacó ininterrumpidamente durante 15 minutos el palacio de gobierno. Los cohetes vés de las radioemisoras autorizadas a seguir transmitiendo y conectadas por cadena nacional. Con Valparaíso ocupado militarmente y el país en estado de excepción constitucional, la población con mayor compromiso político con el gobierno derrocado comenzó a buscar refugio para evitar su detención, ocultándose en los sectores periféricos de la ciudad.

Ese día fue horrible. Horrible (...) Muchos jóvenes de la Universidad Santa María, de la Universidad Católica -muchas personas también- se fueron a esconder en el jardín, a donde nosotros. Por los coligües, por las matas y en el bosque del diablo. (Persona mayor, 82 años)

Los bandos difundidos por los medios de comunicación bajo control militar convocaron a las autoridades, militantes destacados o simpatizantes claves del gobierno derrocado a presentarse ante las nuevas autoridades. Las acciones militares se desplegaron buscando cerrar las vías de salida de la ciudad, para iniciar las tareas represivas de detención de personas, eventual confiscación de armas de fuego, búsqueda de información estratégica sobre militantes de partidos políticos y funcionarios de reparticiones públicas, incautación de literatura o música considerada subversiva y cualquier otra evidencia que representara simpatía por el gobierno derrocado. "En la variante a Viña (del Mar) aparece una cantidad inmensa de marinos (...) Y comienzan los allanamientos" (Persona mayor, 81 años).

La característica topografía de Valparaíso, plena de cerros, quebradas y flora nativa también se volvió sospechosa. Aquellos lugares podían ser propicios para que se ocultaran personas buscadas por los militares.

Cuando nos allanaron a nosotros, nos preguntaban por el bosque del diablo. A mi esposo lo dejaron adentro con mis niños. A míme sacaron para afuera y me decían ¿dónde está el bosque del diablo? Y yo les decía, el bosque del diablo es

rockets que se utilizaron en esa ocasión destruyeron el edificio y ocasionaron un incendio estructural que afectaron gravemente sus instalaciones y los edificios contiguos, por efecto directo de las ondas expansivas. Finalizado el bombardeo, la Moneda fue asaltada por fuerzas militares, encontraron el cadáver del Presidente Allende, que se había suicidado durante el ataque y procedieron a apresar a los sobrevivientes. Al día siguiente, los medios de prensa de todo el país mostraban en sus portadas las dantescas imágenes del bombardeo, confirmando el derrocamiento del gobierno constitucional (Cavallo et al., 1988). 
de la aviación. Para abajo. Para Santos Ossa. De la aviación para acá. No, me decían. Sabemos que ustedes saben dónde es el bosque del diablo. Ese es el bosque del diablo. Y de ahí no me sacaron más. (Persona mayor, 67 años)

c) Período inmediatamente posterior a la ocurrencia del Golpe de Estado.

En los días posteriores al Golpe de Estado la ciudad profundiza su convulsionada situación de ocupación militar, especialmente en sectores poblacionales de menores ingresos.

\section{Después del golpe, cuando ya empezaron a tomar gente, aquí se sentía. Por ejemplo, cuando llegaban en la noche hacían una operación, creo que le llamaban operación candado. No sé cómo le decían, venían militares de arri- ba, militares de abajo, por todos lados. Y llegaban, no sé, unas personas que traían una lista, se las llevaban. (Persona mayor, 78 años)}

Ante la evidencia de los avances militares en el espacio urbano, se instaló un creciente clima de miedo entre las familias. La ciudad, el barrio, el hogar ya no eran un refugio significativo, sino que por el contrario, representaban espacios vulnerables por la fuerza de la represión.

\begin{abstract}
Yo no quisiera entrar mucho en detalle. Pero realmente nosotros la sufrimos harto. Porque estábamos todo el día con los cosacos que nos apuntaban la casa. Casi veíamos el cañón del fusil que entraba por la ventana. Así que fue bastante espantoso, teníamos miedo, mucho miedo. (Persona mayor, 74 años)
\end{abstract}

Los precarios esfuerzos de protección que despliegan los partidarios del gobierno derrocado se enfrentan a las acciones represivas desplegadas por las nuevas autoridades de facto. De manera permanente se revisan los intersticios de la ciudad para encontrar personas comprometidas con el gobierno derrocado, consideradas peligrosas por la ideología a la que adhieren o por las potenciales acciones de resistencia que pudiesen organizar. El Estado de Excepción Constitucional decretado por las nuevas autoridades militares sobrepasa al Estado de Derecho.

Mi hermana comienza a decir sabe, hay señoritas y jovencitos que están por ahí en las quebradas. Entonces fuimos a ver la necesidad de ellos. Entonces mi mami dijo en la tarde, cuando oscurezca tráiganlos y les vamos a hacer comidita y darles. Entonces, empezamos a traer de a poco en la casa de mi mami. Se hacía una olla grande, se les daba comida. Estaban toda la noche y en la mañana, temprano, antes de aclarar ellos se iban al refugio. Se iban para allá. De muchos, no supimos más de ellos. A última hora supimos de tres de ellos. Muchos se tenían que ir. Vivían unos en Santiago, vivían más al norte, más al sur. Estaban estudiando. Después empezaron a llegar. Sabían que nosotros los recibíamos. Llegaba ropa, les traían comida. Un día hubo un soplo, no sé si de vecina. No sé si de ellos mismos que ayudaban. No sé. Fue en la tarde. Había llegado una niña. Esa niña había podido salir. No llegaron las otras. La llevamos para allá y había cinco varones. Justo llegaron. Se dejaron caer los militares por el séptimo de línea, por donde está la escuela. Por arriba. Antes era puro campo. Hicieron cosas terribles. Se los llevaron. Pero antes de llevarse a estos jóvenes, como hacíamos fuego para cocinar, tiraron brasas. Todas las brasas. Hicieron que se sacaran los zapatos. Los hicieron caminar de acá para allá. Mi mami como estaba ahí, la hicieron venir para que ella viera. $Y$ a mis dos hermanos los tenían ahí. $Y$ les dijeron. Eso es para que nunca más hagan esto de tener gente. Los niños gritaban. Yo vivo al frente, al lado de mi hermano y los gritos... terribles. Después los hicieron tirarse al suelo y los más grandes pasaban por arriba del cuerpo. Mi mami... Hasta ahora último, ella no se sacaba la casaca. Porque a ella le pegaron. Por ahí le vimos los moretones. (Persona mayor, 67 años)

Dentro del radio de la ciudad, las instituciones militares, de orden y seguridad, flota naval, reparticiones públicas, centros de salud y recintos universitarios se transformaron en lugares de detención y tortura. "Dentro de las personas que se llevaron, se llevaron a algunos que venían recién saliendo del hospital que todavía tenían la herida aquí, que se les abrió. Y los llevaron para allá, para la intendencia". (Persona mayor, 76 años).

Los efectos del Golpe Militar en Valparaíso produjeron su impacto en el tiempo. El mundo cotidiano familiar y la dinámica de la propia ciudad recogieron sus consecuencias y guardaron en su memoria la profunda fractura histórica, social y urbana que atravesaron sus habitantes. "Los vecinos no eran los vecinos de antes del 73 a después del 73. Ahí hubo un quiebre. Ya el vecino de aquí apenas te saludaba. El otro de más abajo, igual" (Persona mayor, 82 años).

Mi hermano fusilado el 11 de Octubre de 1973. Han pasado casi 46 años y todavía no hay una sentencia firme. Nos cambiaron la vida. Nos cambiaron el proyecto familiar, laboral. Nos cambiaron todo. Y quieren que olvidemos, que demos vuelta la página, que pongamos punto final...es que es imposible. (Persona mayor, 83 años) 


\section{CONCLUSIONES}

El Golpe de Estado de 1973 es el punto cúlmine de una convulsionada etapa que atravesó Chile en su pasado reciente y en la que intervinieron múltiples actores y fuerzas políticas de nivel nacional e internacional. Así entonces, entre los años 1970 y 1973 la triada virtuosa constituida por el Estado, la ciudad y la ciudadanía se fue transformando en una triada en conflicto, en donde el espacio urbano como espacio político de convivencia democrática se vio superado por formas de participación social beligerantes que se manifestaron a través de hostilidades en la ciudad que pusieron en tensión el funcionamiento normativo institucional, llegando en ocasiones a desestabilizar su condición de espacio privilegiado para el ejercicio de la ciudadanía acorde al Estado de Derecho. Como consecuencia, el Golpe de Estado de septiembre de 1973 fue concebido como una intervención militar directa que zanjó el conflicto ciudadano expresado en el espacio urbano, respaldando explícitamente el control del territorio para una de las posiciones en beligerancia. Así entonces, las fuerzas militares ocuparon progresivamente Valparaíso, desde puntos claves en el plan hasta sectores poblacionales en los cerros, en un proceso logístico y estratégico que inmovilizó a toda la ciudad. Lo anterior generó la condición de bando vencedor a las facciones que recibieron el respaldo militar, otorgando la garantía de ocupar el espacio urbano de manera unilateral y decidir sobre la suerte de la población. Con ello, la ciudad como espacio de participación democrática se pulverizó y se profundizó en su condición de espacio de conflicto, siendo imposible acceder a una posición de acuerdo y consenso a partir de la fuerza de los argumentos planteados; sino que se debió enfrentar una posición de explícita beligerancia expresada directamente desde la fuerza de los armamentos desplegados por uno de los bandos en conflicto.

El Estado de Excepción Constitucional anuló al Estado de Derecho y modificó la lectura del territorio desde una lógica cívica hacia una ló- gica militar. En consecuencia, el espacio público dejó de ser organizado desde la convivencia social para ser reorganizado desde la represión. Los paisajes característicos de la ciudad de Valparaíso, definidos desde un anfiteatro natural de cuarenta y dos cerros que rodean concéntricamente la bahía como principal punto de atención, fueron traumáticamente redefinidos como paisajes amenazantes que facilitaban la clandestinidad y la resistencia a través de su caprichosa geografía. Las dependencias de los servicios públicos y de las reparticiones oficiales, concebidas originalmente como espacios destinados a garantizar el ejercicio de la ciudadanía, junto con las reparticiones de las fuerzas armadas y unidades navales, concebidas originalmente como garantes de una constitucionalidad en donde el poder militar queda sometido al poder civil, fueron despojadas de tal condición y sumadas a la infraestructura desde donde se resolvió forzadamente la beligerancia. Su nueva identidad correspondió a lugares de detención, tortura y ejecución sumaria en donde el conflicto urbano escaló hasta su más condenable expresión.

Asegurada la captura militar de los centros estratégicos administrativos de la ciudad, rápidamente la ocupación del territorio se orientó a las zonas portuarias e industriales, fuertemente comprometidas con el gobierno derrocado. Esa ocupación tuvo dos focos de atención. Por una parte, el primer foco correspondió a la infraestructura productiva de la ciudad, concentrada en la zona portuaria ubicada en el borde costero y en la infraestructura industrial ubicada en el plan de la ciudad, sectores que fueron ocupados rápidamente por la fuerza militar y sin mayor resistencia. Por otra parte, el segundo foco correspondió a la población trabajadora que se ubicaba en diversas zonas residenciales, ubicadas preferentemente en la parte alta de la ciudad. A pesar de que esta localización aporta ventajas estratégicas para observar movimientos de personas y vehículos o adoptar medidas de protección, desplazamiento o abastecimiento, estas ventajas no pudieron activarse debido a las férreas disposiciones que establecieron la 
permanencia forzosa en los hogares y la estricta prohibición de circular por la vía pública. En consecuencia, la población fue inmovilizada y reprimida directamente en sus domicilios, desarticulando sus redes de información y apoyo familiar, partidario o comunitario por efectos de la acción militar en los sectores altos. El único código de despeje de sospechas sobre el territorio lo constituyó el izamiento del pabellón patrio como símbolo público de adhesión a la nueva situación del país.

Las familias detenidas de facto en sus hogares por efectos del Estado de Excepción Constitucional, conocieron la delación, la desconfianza y el miedo como las nuevas expresiones de

\section{REFERENCIAS}

Aguilera, C. (2013). Santiago de Chile visto a través de espejos negros. La memoria pública sobre la violencia política del período 19701991 en una ciudad fragmentada. Revista de Estudios Culturales Urbanos Bifurcaciones, 14, 105 128. Recuperado de http://www.bifurcaciones.cl/2013/10/santiago-de-chile-visto-a-traves-de-espejos-negros/

Agüero, F. (2003). 30 años después: La ciencia política y las relaciones Fuerzas Armadas, Estado y sociedad. Revista de ciencia política, 23(2), 251-272. Recuperado de https://scielo. conicyt.cl/scielo.php?script=sci_abstract\&pi$d=$ S0718-090X2003000200013\&lng=en\&nr$\mathrm{m}=\mathrm{iso} \& \mathrm{t} \operatorname{lng}=\mathrm{es}$

Alba, M. (2010). Memoria urbana y experiencia de vida de los ancianos. Presentación. Alteridades, 20(39), 1-6. Recuperado de http://www. scielo.org.mx/pdf/alte/v20n39/v20n39a1.pdf

Alguacil, J. (2008). Espacio público y espacio político: La ciudad como el lugar para las estrategias de participación. Polis, 7(20), 199-223. Recuperado de https://scielo.conicyt.cl/scielo.php?script=sci_arttext\&pi$d=S 0718-65682008000100011$

Arellano G, J.C. (2009). El Partido Nacional en Chile: su rol en el conflicto político (1966-1973). convivencia social instaladas traumáticamente el día del Golpe de Estado y que acompañaron los años venideros de la ciudad y del país sometido a condiciones dictatoriales, evidenciando la imposibilidad de ejercer la democracia desde el espacio público urbano. La memoria de la ciudad es un corolario que reconoce en el Golpe de Estado un hito que fracturó la polis a través de la ruptura del espacio político ciudadano debido a la intervención militar y que como consecuencia, retuvo a las relaciones entre el Estado y la ciudadanía dentro de un marco dictatorial de 17 años de duración, aportando un complejo legado de confrontación urbana definida desde el conflicto y la hostilidad.

Atenea, (499), 157-174. Recuperado de https:// scielo.conicyt.cl/scielo.php?script=sci_arttext\&pid=S0718-04622009000100010\&ln$\mathrm{g}=\mathrm{en} \& \mathrm{nrm}=\mathrm{iso} \& \mathrm{t} \operatorname{lng}=$ en

Aróstegui, J. (2004). La historia vivida. Sobre la historia del presente. Madrid: Alianza Editorial.

Campos, L. y López, L. (2004). Identidad y memoria urbana. Recuerdo y olvido, continuidades y discontinuidades en la ciudad. Revista de Urbanismo, 10. Recuperado de http://web. uchile.cl/vignette/revistaurbanismo/CDA/ urb_completa/0,1313,ISID\%253D488\%2526IDG\%253D2\%2526ACT\%253D0\%2526PRT\%253D11429,00.html

Cavallo, A.; Salazar, M. y Sepúlveda, O. (1988). La historia oculta del régimen militar. Santiago de Chile. Ediciones La Época.

Carrión, F. (2007). El desafío político de gobernar una ciudad. Revista Nueva Sociedad, 212(6), 36-52. Recuperado de https://nuso.org/articulo/el-desafio-politico-de-gobernar-la-ciudad/

Cortés, A. (2014). El movimiento de pobladores chilenos y la población La Victoria: ejemplaridad, movimientos sociales y el derecho a la ciudad. EURE, 40(119), 239-260. Recuperado de https://scielo.conicyt.cl/scielo.php?script=sci_arttext\&pi- 
$d=S 0250-71612014000100011 \& \operatorname{lng}=e n \& n r-$ $\mathrm{m}=\mathrm{iso} \& \operatorname{lng}=\mathrm{en}$

Cruz, M. (2003). Tiempo de narratividad. El sujeto, entre la memoria y el proyecto. Documento de Trabajo $N^{0}$ 2. Valparaíso: Taller de Epistemología Social. Facultad de Humanidades, Universidad de Valparaíso.

Franco, L. (2003). Violencias, conflictos urbanos y guerra civil. El caso de la ciudad de Medellín en la década del noventa (pp 50-102). En Violencias y conflictos urbanos. Un reto para las políticas públicas. Medellín: Instituto Popular de Capacitación. Recuperado de http://biblioteca.clacso.edu.ar/Colombia/ipc/20121210114850/ violencias.pdf

Haesbaert, R. (2013). Del mito de la desterritorialización a la multiterritorialidad. Cultura y representaciones sociales, 8(15), 9-42. Recuperado de http://www.scielo.org.mx/scielo.php?script=sci_arttext\&pid=S2007-81102013000200001\&l$\mathrm{ng}=\mathrm{es} \& \mathrm{t} \operatorname{lng}=\mathrm{es}$

Halbwachs, M. (1997). La mémorie collective. Paris: Albin Michel.

Hernández Aja, A. (2000). Barrios y equipamiento públicos, esencia del proyecto democrático de la ciudad. Documentación Social de Caritas Española, 119, 79-93. Recuperado de http:// oa.upm.es/14232/1/2000_Agust\%C3\%ADn_ Hernandez_Documentacion_social_119_Barrios_y_Equipamientos_Publicos.pdf

Kornbluh, P. (2004). Pinochet: los archivos secretos. Barcelona: Crítica

Leal, F. (2003). La doctrina de seguridad nacional. Materialización de la Guerra Fría en América del Sur. Revista de Estudios Sociales, 15(2),
74-87. Recuperado de https://revistas.uniandes.edu.co/doi/pdf/10.7440/res15.2003.05

Lira, E. (2013). Algunas reflexiones a propósito de los 40 años del Golpe Militar en Chile y las condiciones de la reconciliación política. Psykhe, 22(2), 5-18. Recuperado de https:// scielo.conicyt.cl/pdf/psykhe/v22n2/art02.pdf

Membrado, M. (2010). Experiencias de envejecer y experiencias urbanas. Un estudio en el suroeste francés. Alteridades, 20(39), 57-65. Recuperado de http://www.scielo.org.mx/ pdf/alte/v20n39/v20n39a5.pdf

Raposo, G. (2012). Territorios de la memoria: La retórica de la calle en Villa Francia. Polis, 11(31), 203-222. Recuperado de https://scielo. conicyt.cl/scielo.php?script=sci_arttext\&pi$d=S 0718-65682012000100012 \& \operatorname{lng}=e s \& n r-$ $\mathrm{m}=$ iso\&tlng=es

Reguillo Cruz, R. (1991). En la calle otra vez. Las bandas: identidad urbana y usos de la comunicación. Instituto Tecnológico y de Estudios Superiores de Occidente (ITESO), México.

Unidad Popular (1970). Programa básico de gobierno de la Unidad Popular. Candidatura Presidencial de Salvador Allende. Recuperado de http://www.memoriachilena.gob.cl/602/ w3-article-7738.html

Valles, M. (2002). Entrevistas cualitativas. Centro de Investigaciones Sociológicas. Serie Cuadernos Metodológicos. Madrid Ediciones CIS.

Waldman, G. (2009). Chile. La persistencia de las memorias antagónicas. Política y Cultura, 31, 211-234. Recuperado de http://www.scielo.org.mx/scielo.php?script=sci_abstract \&pi$\mathrm{d}=$ S0188-77422009000100011\&lng=pt\&nrm=iso

Patricia Castañeda Meneses es Trabajadora Social y Licenciada en Trabajo Social por la Universidad de Valparaíso, Chile. Magister en Ciencias Sociales Aplicadas por la Universidad de La Frontera, Chile. Magister en Ciencias de la Educación, Mención Desarrollo Social por la Universidad París XII, Val de Marne, Francia. Doctora en Ciencias de la Educación por la Universidad de Barcelona, España. Especialista en Formación Profesional de Trabajo Social, Metodologías de las Ciencias Sociales, Derechos Humanos y Memoria Colectiva. Actualmente se desempeña como Académica e Investigadora de la Escuela de Trabajo Social de la Facultad de Ciencias Sociales de la Universidad de Valparaíso, Chile. Avda. Colón 2128 (CP 2340000) Valparaíso, Chile, patricia.castaneda@uv.cl 
Ketty Cazorla Becerra es Trabajadora Social y Licenciada en Trabajo Social por la Universidad de Valparaíso. Magister en Salud Pública por la Universidad de Valparaíso. Especialista en Salud Pública, Atención Primaria de Salud y Territorio, Salud Mental y Participación Social en Salud. Actualmente se desempeña como Académica e Investigadora de la Escuela de Trabajo Social de la Facultad de Ciencias Sociales de la Universidad de Valparaíso, Chile. Avda. Colón 2128 (CP 2340000) Valparaíso, Chile, ketty.cazorla@uv.cl

Katherine Cuevas Lang es Trabajadora Social y Licenciada en Trabajo Social por la Universidad de Valparaíso. Magister en Salud Pública por la Universidad de Valparaíso. Especialista en Salud Pública, Salud Familiar y Gestión en Salud. Actualmente se desempeña como Académica e Investigadora del Departamento de Salud Pública de la Escuela de Medicina de la Universidad de Valparaíso, Chile. Avda. Angamos 655 (CP 2520000) Reñaca, Viña del Mar, Chile, katherine.cuevas@uv.cl 